\title{
Design and implementation of an automatic control for a laptop battery charger
}

\author{
Agus Ramelan ${ }^{1}$, M Adli Rizqulloh², and Dadang Lukman Hakim ${ }^{3}$ \\ ${ }^{1}$ Bandung Institute of Technology, School of Electrical Engineering and Informatics, Indonesia \\ ${ }^{2}$ Universitas Pendidikan Indonesia, Department of Electrical Engineering Education, Indonesia
}

\begin{abstract}
In the process of charging laptop's battery, there is no automatic settings are disconnected and connecting the laptop charger voltage according to the needs and desires of the user. In addition, the apathetic nature of the laptop users often also lead to battery charging voltage overload on the laptop battery. These conditions will have an impact on the voltage of the battery leakage which will eventually be more easily damaged. In addition, the electrical energy will continue to flow from adaptor to the laptop and the resulting dissipation of electrical energy within a certain period. From some of these problems, the authors had the idea to make the tool as a form of solution that charging automatic controller. The tool is designed to regulate battery-charging time through additional software on the laptop. The method used was an experimental method. Results of this research have shown that these tools not only cut off the voltage from the adapter to the laptop, but also classes decide the flow voltage of $220 \mathrm{~V}$ AC power adapter to the charger. Therefore, this tool provides two benefits at once, ie maintain the lifetime of the battery and also save electrical energy use.
\end{abstract}

\section{Introduction}

The background of this research is no automatic setting that disconnects and connects the laptop charger voltage according to the needs and desires of the user. Currently, there is only the automatic battery charging software. However, this software does not disconnect and connect the hardware device from the charger, the adapter. However, there will still be a voltage flow that will be dissipated into heat on the charger adapter. In addition, laptop users tend to be apathetic to battery charging, causing a voltage overload on the laptop battery. This condition will affect the leakage voltage on the battery that eventually the battery will be more quickly damaged.

Battery degradation modeling can be categorized into theoretical models and empirical models. Theoretical models have been described in many research, e.g [1], focus on the loss of active lithium ions due to solvent reduction reaction and on the rise of the anode film resistance. While the empirical model, [2], it capture the characteristics of real-life batteries, and can be used to predict their behavior under various operating conditions. We do not focus on the modeling, but rather to know how the relationship between the state of charge (SoC) and battery life cycle. Figure 1 shows the features of a very general capacity versus cycle number plot.

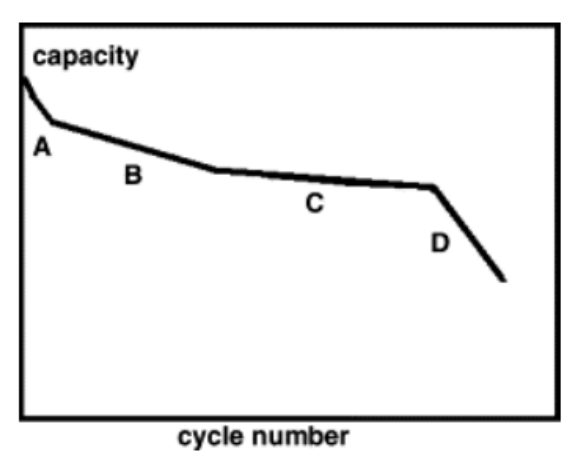

Fig. 1. General capacity degradation behavior of lithium-ion batteries [3].

Figure 2 illustrates dynamic stress tests (DST) reflecting capacity loss when cycling Li-ion at a various charge and discharge bandwidths. The largest capacity loss occurs when discharging a fully charged Li-ion to 25 percent SoC (black color curve); the loss would be higher if fully discharged. Cycling between 85 and 25 percent (green color curve) provides a longer service life than charging to 100 percent and discharging to 50 percent (dark blue color curve). The smallest capacity loss is attained by charging Li-ion to 75 percent and discharging to 65 percent. High voltages and exposure to elevated temperature are said to degrade the battery quicker than cycling under normal condition [4].

\footnotetext{
* Corresponding author: agusramelan16@gmail.com
} 


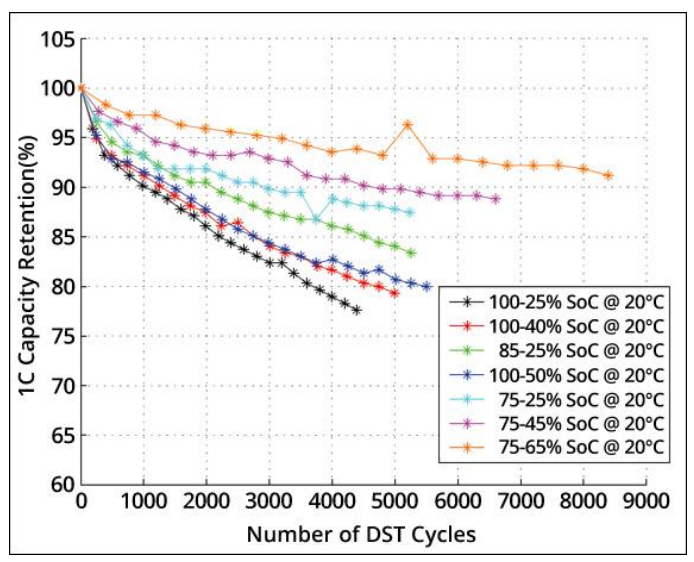

Fig. 2. Capacity loss when operating Li-ion within given charge and discharge bandwidths [5].

In addition, electrical energy will also continue to flow from the adapter to the laptop. However, it will also result in wastage of electrical energy in a certain period of time. Indeed if only one laptop will not dispose of electrical energy in a large quantity that is only about 2.7 watts [6]. However, if there are 10 million laptop users who are negligent in regulating the time of charging the battery then there will be 2.7 million watts of wasted electrical energy in vain.
From those problems above, the authors have an idea to make the controller device charging laptop battery automatically. This tool is designed to adjust the battery charging time through an additional software on the laptop. This tool not only disconnects the voltage flow from the adapter to the laptop but also disconnects the voltage flow from $220 \mathrm{~V}$ AC power to the charger adapter. Because it provides two benefits at once, namely maintaining the durability of the battery and also save the use of electrical energy.

\section{System design}

\subsection{Hardware}

The hardware part of this device consists of several components. There are Zener diode 3.6V, Resistor 682 , Resistor 2k2, Resistor 10k2, Resistor 1k2, KSP2N2222A Transistor, Diode $1 \mathrm{n} 4004$, Relay 5v, Terminal block 2 pins, Led red 3mm, ATmega8, Crystal 12MHz, 22pF 2 ceramic capacitor, $10 \mathrm{uF}$ Electrolit condensator, and Type B USB connector. Figure 3 shows the system circuit oh the hardware device.

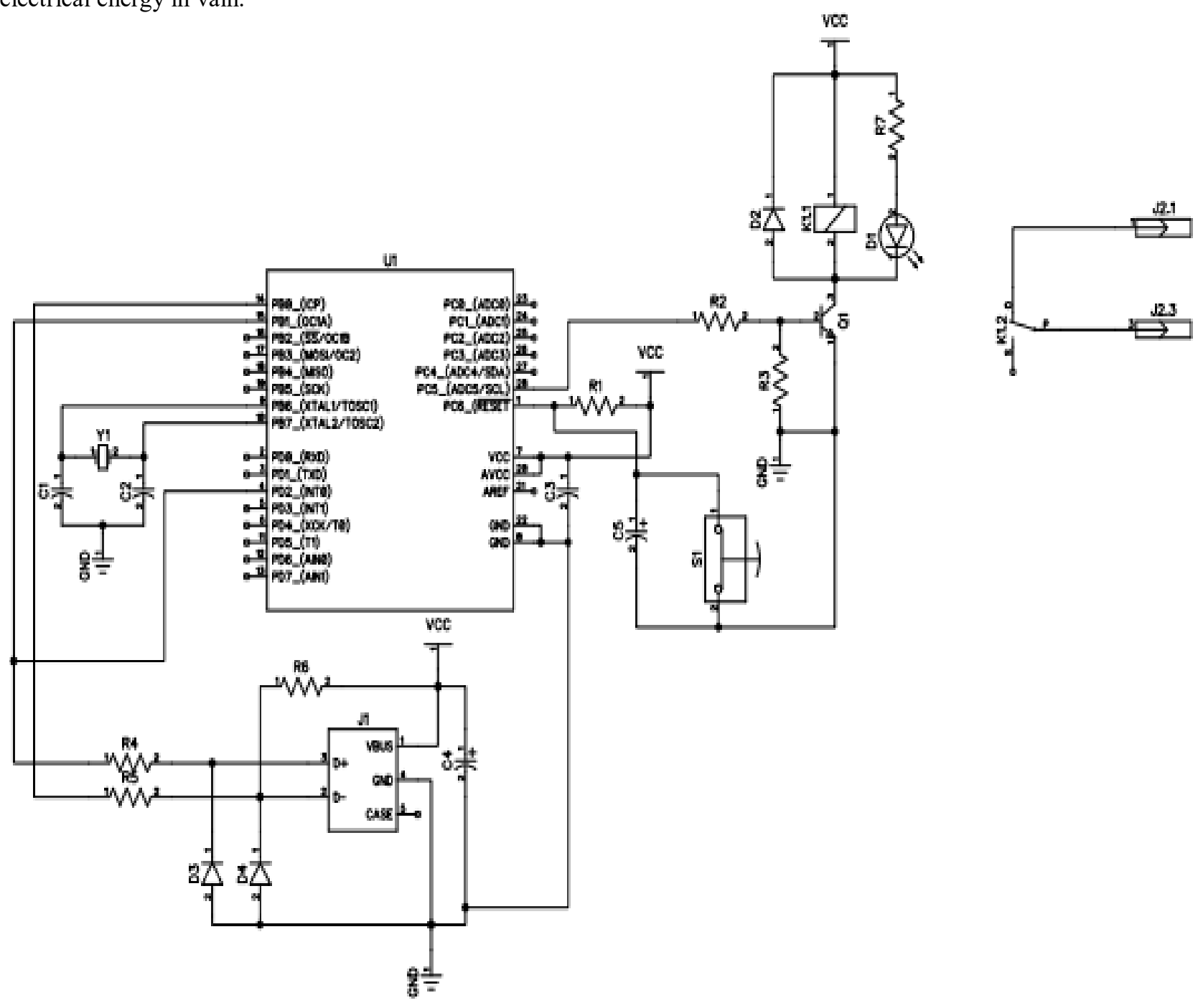

Fig. 3. The design of the system circuit. 
The microcontroller can not directly control the relay because the output current of its pins are only capable of delivering $20 \mathrm{~mA}$, while the relay component needs the current of about $60 \mathrm{~mA}$. Therefore an interfacing component between the relay and microcontroller is required. There are many ways of interfacing between microcontroller and relay, one of them is using NPN transistor component which functioned as a switch [7]. The relay is an inductive component so that when the relay is turned off it will produce a lagging current. While the transistor is a component derived from semiconductor materials, so susceptible to damage when faced with lagging current. Therefore on the relay component is installed diode. Diodes mounted on relay components serve as a snubber. The snubber diode serves as the discharge of the lagging current generated by the relay coil so that the transistor component will be in a safe state from the lagging current.

\subsection{Software}

The software consists a transmitter and a receiver. In the interfacing with the computer, we use Visual Basic Express 2010 software from Microsoft. Programming using visual basic has supported GUI (Graphical User Interface) so it will be easier to use by the user. Visual Basic uses basic language which is a high-level language in a programming language, which means that the command in the basic language is very close to everyday human language [8]. Therefore, basic languages include programming languages that are easy to learn.

In general, this software on the transmitter consists of two main programs. That is the program reading the battery status and signal sender program to the hardware part. At the time, the program is opened then it will initialize all the variables that exist. After that, it will check the existence of battery on the laptop. If not found the existence of the battery then it will show an error message box automatically. If a battery is found on a laptop, the user must enter the lower limit and upper limit of the battery. It will read the status of the laptop battery. If the status has reached a certain limit then it will check the connection between laptop and hardware, if there is an error on the connection then it will go out by itself. Meanwhile, if the connection between the laptop and the hardware part is in good condition then it will send a command signal. The working principle of the program can be explained through the following flowchart in Figure 4.

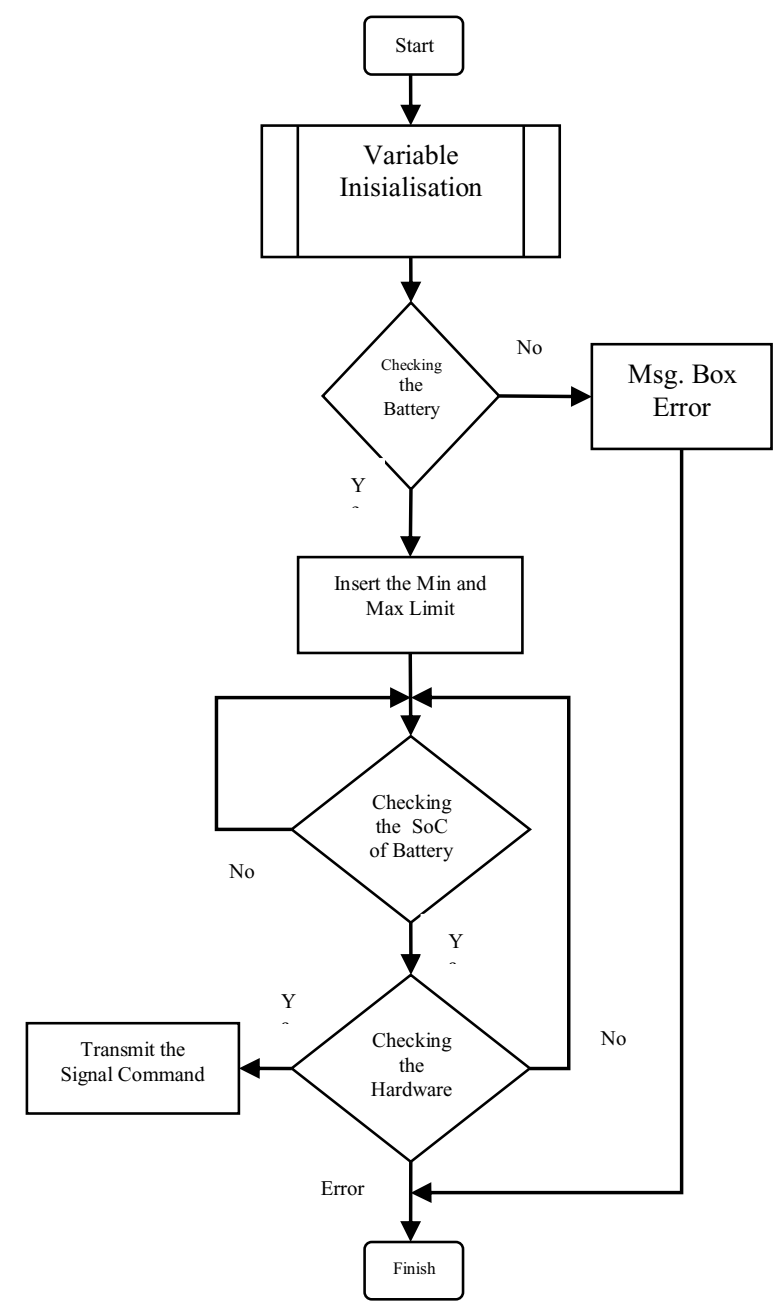

Fig. 4. The flowchart of Software System.

\section{Experimental result}

The hardware consists of three main parts: a power cable, a virtual communication cable (USB cable), and a controller. Hardware on this device to connect or disconnect power on the adapter.

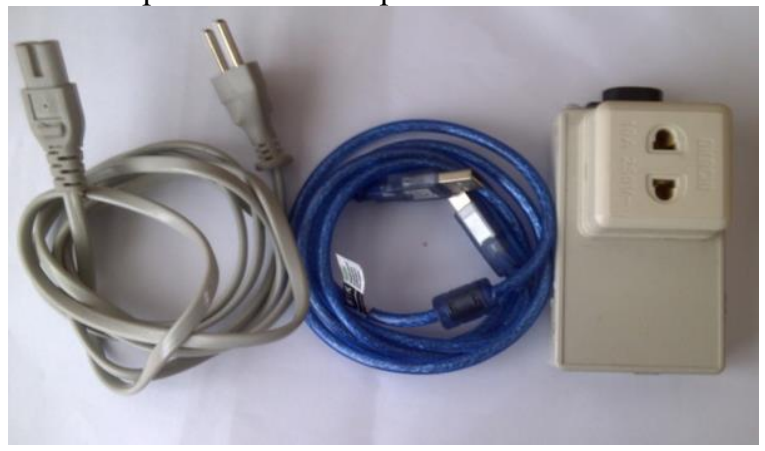

Fig. 5. The hardware of Automatic Control for Laptop Battery Charger.

In the computer interfacing (data transmitter), we use Visual Basic Express 2010 software from Microsoft. The software design of the computer interfacing can be seen in the following Figure 6.

\footnotetext{
Corresponding author: agusramelan16@gmail.com
} 


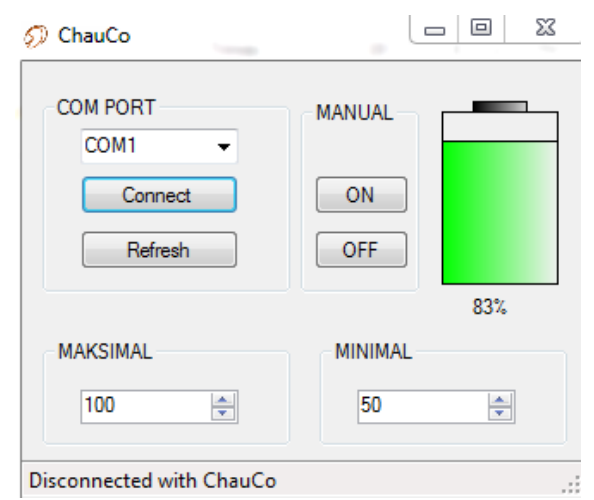

Fig. 6. The Computer Interfacing (program) of Automatic Control for Laptop Battery Charger.

In the program column, figure 6, there is a COM Port column as the USB cable port detector, a connect button, an input column for the maximal and minimal limit, and a color display of the battery charging status of the laptop (the battery SoC). The working principle of the $\mathrm{V}$ USB program in this tool can be explained in the following flowchart in Figure 7.

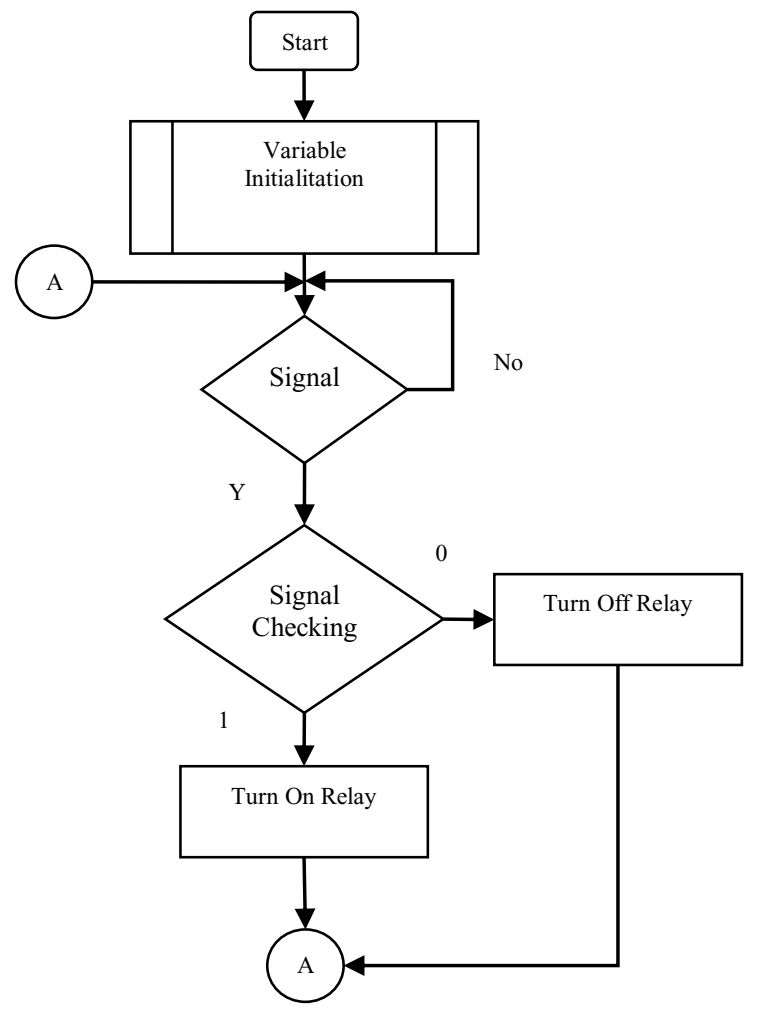

Fig. 7. The working principle of the V-USB program.

While the program is opened, it will initialize all the variables that exist. After that, it will check the existence of the battery on the laptop. If not found the battery then the program will show an error message box automatically. When the battery is found on the laptop, the user must enter the lower limit and the upper limit of desired charging. It will read the status of the battery (state of charge). If the status has reached the certain limit then the program will check the connection between laptop and hardware, if there is an error on the connection then the program will go out by itself. Meanwhile, if the connection between the laptop and the hardware part is in good condition then it will send a command signal.

The main function of this device is to avoid overcharging of batteries that can shorten the cycle life of the battery. However, this device can also save an electricity usage. This is because it directly disconnects the power supply used by the adapter when the battery is in full state.

The advantages of using this device when compared with those who do not use it are as follows.

- The laptop battery will be more durable.

- It can save the electricity usage.

- The adapter will be more durable.

- The user will be more focus on doing the task, without worrying about battery condition.

\section{Conclusion}

This device controls battery charging automatically and saves excessive power consumption because the user does not unplug the laptop charger adapter when the battery condition is full. It consists of two main parts, namely software part and hardware part. Both parts are tied together and supported, however this device can not work if there is damage to either software or hardware.

\section{References}

1. G. Ning and B. N. Popov, Cycle life modeling of lithium-ion batteries, J. of The Electrochemical Society, vol. 151, no. 10, pp. A1584-A1591, (2004)

2. O. Erdinc, B. Vural, and M. Uzunoglu, A dynamic lithium-ion battery model considering the effects of temperature and capacity fading, in Clean Electrical Power, 2009 International Conference on. IEEE, pp. 383-386 (2009)

3. R. Spotnitz, Simulation of capacity fade in lithiumion batteries, J. of Power Sources, vol. 113, no. 1, pp. 72-80, (2003)

4. Battery University. BU-808: How to Prolong Lithium-based Batteries. (online) Available at: http://batteryuniversity.com/learn/article/how_to_pr olong_lithium_based_batteries

5. X. Bolun, O. Alexandre, U. Andreas, A. Göran, Kirschen, D. Modeling of Lithium-Ion Battery Degradation for Cell Life Assessment. IEEE Transactions on Smart Grid. 99. 1-1. 10.1109/TSG.2016.2578950. (2016)

6. R. Ainul, Analisis Perbandingan Sistem Kelistrikan $A C$ dan DC pada Jaringan Tenaga Rendah. (Skripsi Universitas Indonesia, Depok, 2012)

7. H. Wicaksono, Catatan Kuliah "Automasi 1", (Teknik Elektro Universitas Kristen Petra)

8. Arif J T. Modul Dasar Pemrograman 2 Dengan Visual Basic. (Universitas Muhammadiyah Purwokerto) 